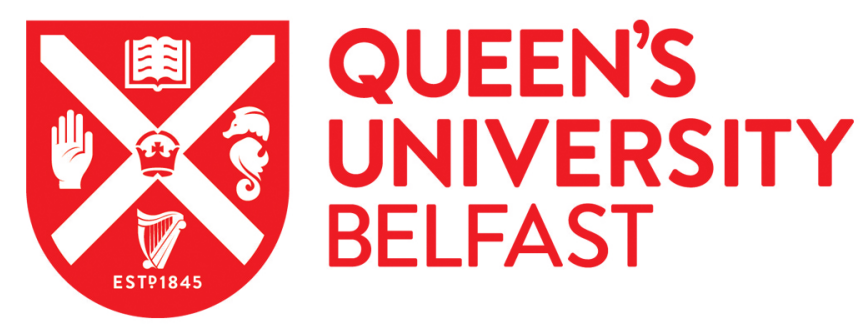

\title{
Theoretical vertical-axis tidal-current-turbine wake model using axial momentum theory with CFD corrections
}

Ma, Y., Lam, W-H., Cui, Y., Zhang, T., Jang, J., Sun, C., Guo, J., Wang, S., Lam, S. S., \& Hamill, G. (2018).

Theoretical vertical-axis tidal-current-turbine wake model using axial momentum theory with CFD corrections. Applied Ocean Research, 79, 113-122. https://doi.org/10.1016/j.apor.2018.07.016

Published in:

Applied Ocean Research

Document Version:

Peer reviewed version

Queen's University Belfast - Research Portal:

Link to publication record in Queen's University Belfast Research Portal

Publisher rights

(c) 2018 Elsevier Ltd. All rights reserved.

This manuscript version is made available under the CC-BY-NC-ND 4.0 license http://creativecommons.org/licenses/by-nc-nd/4.0/,which permits distribution and reproduction for noncommercial purposes, provided the author and source are cited

\section{General rights}

Copyright for the publications made accessible via the Queen's University Belfast Research Portal is retained by the author(s) and / or other copyright owners and it is a condition of accessing these publications that users recognise and abide by the legal requirements associated with these rights.

Take down policy

The Research Portal is Queen's institutional repository that provides access to Queen's research output. Every effort has been made to ensure that content in the Research Portal does not infringe any person's rights, or applicable UK laws. If you discover content in the Research Portal that you believe breaches copyright or violates any law, please contact openaccess@qub.ac.uk. 


\title{
Theoretical vertical-axis tidal-current-turbine wake model using axial momentum theory with CFD corrections
}

Yanbo $\mathrm{Ma}^{12}$; Wei Haur $\mathrm{Lam}^{12}$ *; Yonggang Cui ${ }^{12}$; Tianming Zhang ${ }^{12}$; Jinxin Jiang ${ }^{12}$; Chong Sun ${ }^{12}$; Jianhua Guo ${ }^{12}$; Shuguang Wang ${ }^{12}$; Su Shiung Lam ${ }^{3}$; Gerard Hamill ${ }^{4}$

${ }^{1}$ State Key Laboratory of Hydraulic Engineering Simulation and Safety, Tianjin University, People's Republic of China.

${ }^{2}$ First R\&D Services, A-08-16 M Suites, 283 Jalan Ampang, 50450 Kuala Lumpur, Malaysia.

${ }^{3}$ Pyrolysis Technology Research Group, Eastern Corridor Renewable Energy Group (ECRE), School of Ocean Engineering, Universiti Malaysia Terengganu, 21030 Kuala Nerus, Terengganu, Malaysia.

${ }^{4}$ School of Natural and Built Environment, Architecture, Civil \& Structural Engineering and Planning, Queen's University Belfast, David Keir Building, Stranmillis Road, Belfast, BT9 5AG, United Kingdom.

Corresponding email: wlam@tju.edu.cn

\begin{abstract}
The wake from a tidal current turbine has a significant impact on a tidal farm. A single turbine wake would affect the turbine located adjacent or downstream. Two equations are proposed to predict the mean velocity within the wake of a vertical-axis turbine. The first equation used to predict the efflux velocity is derived based on the axial momentum theory and dimensional analysis. Efflux velocity is the minimum velocity closest to the turbine downstream. The second equation used to predict the lateral velocity distribution is derived based on Gaussian probability distribution. The predictions are compared with the existing experimental and numerical results. Validation of the equations gives a variation in the range of $0-1.13 \%$ for the efflux velocity by comparing the proposed theoretical works and Dai and Lam's experimental measurements. These equations are the foundation of the analytical method for wake prediction of a vertical-axis turbine.
\end{abstract}

Keywords: Ocean engineering; ocean energy, marine renewable energy, vertical-axis turbine; tidal current turbine; wake model 


\section{Introduction}

The heavy use of fossil fuels is exacerbating environmental pollution and climate warming with the development of the world economy. Researchers investigate the replacement using renewable energy and proposed that marine renewable energy has great potential due to its broad ocean areas [1]. Harnessing marine renewable energy is challenging due to the harsh operating condition in ocean. In general, marine renewable energy includes ocean tides, ocean waves, tidal current, temperature gradient and salinity gradient energy [2]. Ocean wave energy is the energy of moving and elevated water within a wave. Tidal and current energy is the kinetic energy in moving water, such as ocean current stream or tidal current. Ocean thermal energy is the energy recoverable in the temperature gradient between the warm surface water and the cold deep water. Salinity gradient energy is the energy obtained from the salinity gradient between the waters from different regions. Tidal current energy has made good progress these years, among the aforementioned five forms of marine renewable energy, owing to its predictability and higher density of water compared to wind. Tidal current energy is the potential types of marine renewable energy and is expected to give significant contribution to future mix of the energy supply [3].

Tidal current turbine is the essential device used to harness the kinetic energy from the tidal current. Incoming flow leads to the rotation of turbine and the induced torque forces due to rotation is being transferred to the generator for electricity. Rotating turbine disturbs the incoming water flow producing the wake downstream. The wake behind a tidal current turbine has significant impact on the velocity field downstream. A tidal current turbine could extract kinetic energy of flowing water and induce a velocity deficit downstream. The velocity deficit influences the performance of turbines in tandem that the overall efficiency of the turbine array will be affected. Thus, wake properties of a tidal current turbine should receive more attention and the theory of tidal current turbine wake need to be developed. Experimental, numerical and theoretical methods should be taken to understand the tidal current turbine wake.

Generally, researchers focus more on the efficiency of turbine instead of the wake of turbine. Wei et al. conducted a series of experiments to investigate the influence of blade pitch angle and axial distance on the performance of the counter-rotating type horizontal-axis tidal turbine and found that the proper increase of blade pitch angles and axial distance could enhance the performance of a counter-rotating turbine by increasing the peak power coefficient value and widening high power coefficient value area [4]. Liu et al. used both analytical and numerical methods to predict the effects of blade twist and nacelle shape on the performance of horizontal axis tidal current turbines [5]. Wang et al. analysed how the yawing frequencies affect the main hydrodynamic coefficients of the turbine [6]. Liu et al. conducted experimental model tests to predict the performance of two sets of metal and plastic bidirectional tidal turbine rotors [7]. The numerical results showed that the application of optimised hydrofoils improve the power efficiency with better flow separation around hydrofoil. However, the research on turbine efficiency is connected to the understanding of the 
surrounding flow field. Flow field investigation is also required to understand the wake structure. The investigation of velocity field within a turbine wake is therefore significant to increase the overall performance of tidal turbine farm.

Recently, researchers conducted experiments to investigate velocity within a turbine wake. Atcheson et al. conducted an experiment to measure the performance and wake characteristics of a $1: 10^{\text {th }}$ scale horizontal-axis turbine in steady uniform flow conditions, and found that increasing the inflow velocity from $0.9 \mathrm{~m} / \mathrm{s}$ to $1.2 \mathrm{~m} / \mathrm{s}$ influenced the turbulent wake characteristics more markedly and the flow field in the wake of a horizontal-axis tidal turbine is strongly affected by the turbine support structure [8]. Wang proposed the energy coefficient factor to include the tip speed ratio and solidity of turbine to better predict the velocity field within a horizontal-axis turbine wake [9]. Seo et al. conducted model tests for power and wake measurements in a towing tank facility to investigate conversion of kinetic energy of the turbine wake and decomposed it into effectively extracted work, loss due to the drag on the turbine system, kinetic energy of the time-mean axial flow, local flow structures, turbulence, and secondary flow loss [10]. Experimental methods are important to obtain the data of the velocity within the wake of the tidal current turbine.

Numerical simulations also be applied to predict turbine wake properties. Sufian et al. made a CFD model to simulate impacts from a horizontal-axis tidal turbine under combined surface waves and a steady current. Results showed that the wave-periodaveraged velocities were similar to those in the steady-current-only condition [11]. Mohammad et al. used the hybrid LES/ALM technique to investigate the wake of a laboratory scale tidal stream turbine in a shallow water channel, it revealed that the distinct characteristics of the streamwise changes of turbulence intensity or turbulent kinetic energy might serve as an effective indicator for the flow regime transition and wake behaviour [12]. Bromm et al. performed simulations to investigate the impact of directionally sheared inflow on the wake development behind a single wind turbine and to analyse the impact of the wakes on the energy yield and loading of a downstream turbine [13]. Results showed that directionally sheared inflow led to a non-symmetrical wake development, which transferred to distinct differences in the energy yield and loading of downstream turbines of equal lateral offsets in opposite direction. Numerical simulation is another method to study on the wake of the tidal current turbine.

As for theoretical equations to predict a turbine wake, Lam et al. proposed two equations to predict velocity within a horizontal-axis turbine wake. One is used to predict the efflux velocity of a turbine wake, which is based on the axial momentum theory [14]. The other one is used to predict the lateral velocity distribution downstream, which is based on Gaussian probability distribution. These equations could accurately predict velocity within a horizontal-axis turbine wake. However, no equation is available to predict velocity within the wake of a vertical-axis turbine. Theoretical equations are convenient for engineers to investigate the basic condition of the wake of a tidal current turbine quantitatively. This research proposes the theoretical equations 
which could predict velocity within a vertical-axis turbine wake.

\section{Methodology}

Methodologies include the axial momentum theory to deduce the equation and computational fluid dynamics (CFD) methods to conduct the numerical simulation. The axial momentum theory is the theoretical foundation of the deduction of the efflux velocity. Computational fluid dynamics (CFD) methods are used to understand the velocity distribution of the wake. Both of axial momentum theory and CFD are to proposed the theoretical equations for vertical-axis turbine wake.

\subsection{Axial momentum theory}

Froude proposed the axial momentum theory which was based on Rankine's research. The axial velocity component is the most important velocity component of a propeller wake. Tangential velocity component and radial velocity component of wake are smaller compared to the axial velocity component and their effect on wake is less significant. Axial momentum theory takes only the axial velocity component into consideration on the basis of actuator disc model. This model was used to develop the theoretical model for propeller wake. The axial momentum theory has been widely used to predict the efflux velocity of ship propeller wake and the horizontal-axis turbine wake, which includes the following 6 assumptions.

(1) The turbine can be simulated with an ideal equal diameter actuator disc.

(2) The actuator disc is composed of numerous rotating blades, and the blades rotate at an infinite speed.

(3) The thickness of the actuator disc is negligible in the axial direction.

(4) The actuator disc is undisturbed in the ideal fluid (for non viscous fluid);

(5) The fluid is subjected to the same increase of pressure when the fluid flows through the disc.

(6) The energy supplied to the disc can be completely converted into the fluid without any rotation effect.

The axial momentum theory has been widely used to describe the characteristics of ship propeller jets. Albertson et al. studied the velocity field of a jet based on the axial momentum theory [15]. This works were adapted to be the foundation of all propeller jet researches. Blaauw \& van de Kaa, Berger and Verhey et al. agreed that the propeller jet flow consisted of axial, tangential and radial velocity components [16-18]. Hamill et al. used physical propellers to investigate the velocity field of the propeller jet with consideration of the rotation characteristics of the propeller rather than a plain water jet [19-21]. On this basis, Lam observed the flow field distribution of a propeller jet by using the Laser Doppler Anemometry (LDA). The effect of axial velocity, tangential and radial velocity components of the propeller jet is revealed through further investigation using the CFD numerical simulation [22]. Lam innovatively applied the axial momentum theory to the field of the tidal current turbine. The equations proposed by Lam could predict the velocity within the wake of a horizontal-axis turbine. In this 
paper, the axial momentum theory is used to propose the equations used to predict the velocity within the wake of a vertical-axis turbine [23].

\subsection{CFD corrections for wake model}

Partial differential equations are usually used to describe the physical properties of fluid flow. The equations which govern the flow of the fluid are called governing equations. Computational Fluid Dynamics (CFD) can solve the governing equations of fluid mechanics using computer and numerical methods. CFD can also simulates and analyses problems of fluid flow, heat transfer and related transfer. The governing equation for the flow at the macroscopic scale is called the Navier-Stokes equation, which is mainly composed of the continuity equation, the momentum equation and the energy equation. More details of Computational fluid dynamics are shown in the book of Versteegs and Malalasekera [24].

In the current works, the flow field domain of a vertical-axis turbine has been created. The size of turbine model is $1000 \mathrm{~mm}$ in diameter with the blade chord length of $150 \mathrm{~mm}$ for NACA0025 aerofoil. The velocity of the free stream is $2 \mathrm{~m} / \mathrm{s}$. Realizable k-epsilon model and standard wall functions are used to calculate the turbulence model and boundary layers. The calculation is conducted by ANSYS Fluent 15.0. Structured grids are used in the CFD numerical simulation in this paper. ICEM software is used for mesh generation for all calculation domain. The suitable models, mesh and parameter settings are important to ensure the accuracy of CFD calculation. Fig.1 shows the structured grids of the blade. Fig.2 shows the grids of the blade boundary layer. The rotating domain is shown in Fig.3, and the grids of calculation domain is shown in Fig.4. Figs.5 and $\mathbf{6}$ show the contour plot and the vector plot of the flow field of the wake of the vertical-axis turbine. 
Fig. 1. Structured grids of the blade of a vertical-axis tidal turbine

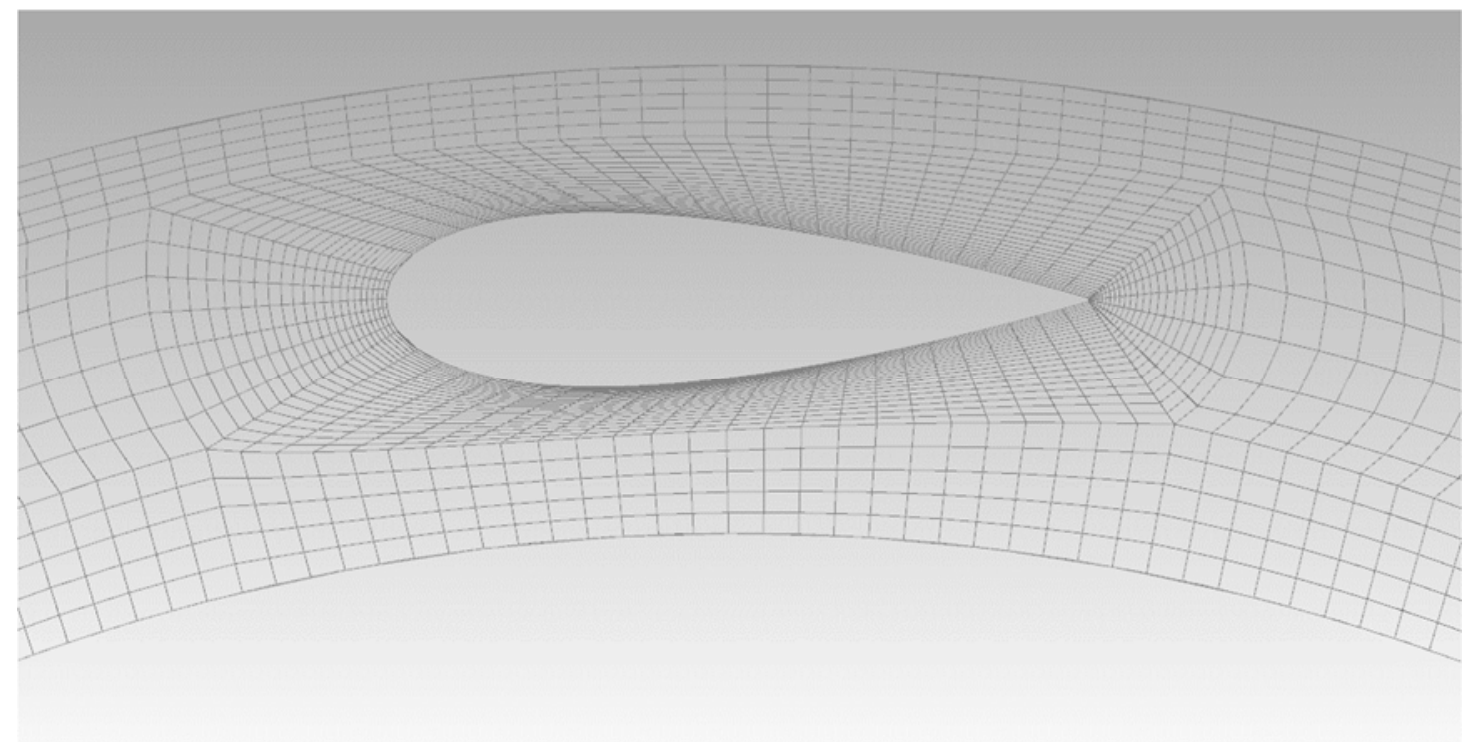

Fig. 2. Structured grids of the boundary layer of the flow field around the blade

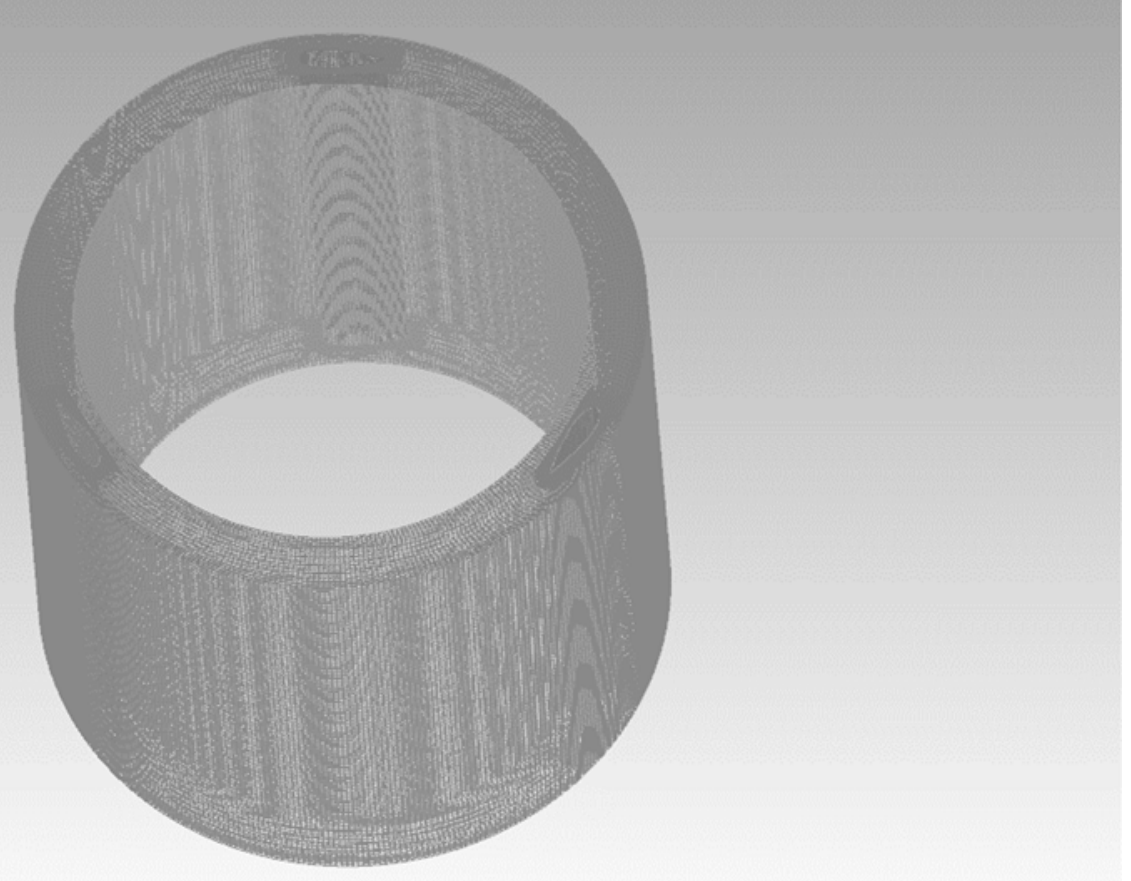

Fig. 3. Structured grids of the rotating domain of the flow field 
Fig. 4. Structured grids of the calculation domain

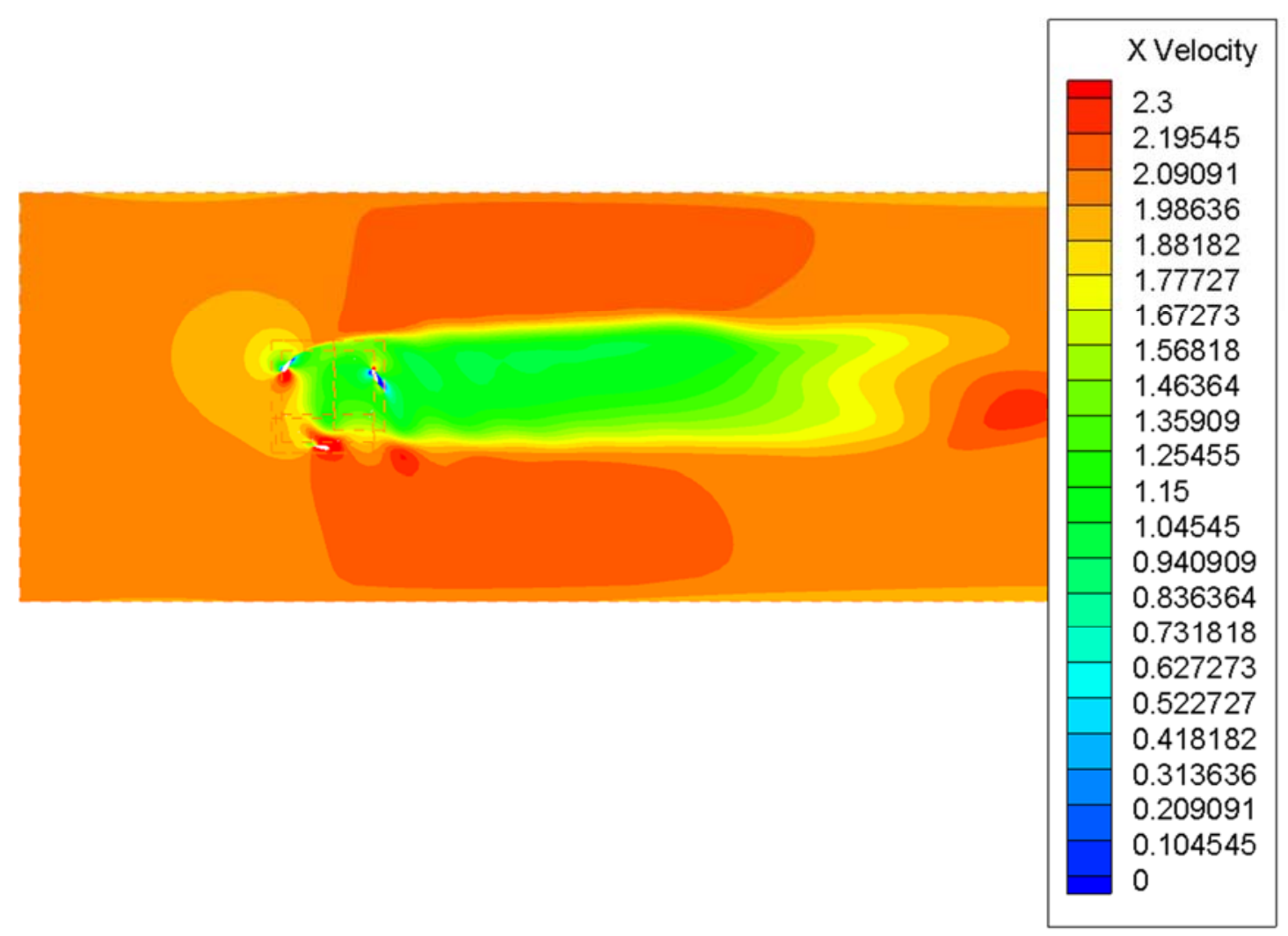

Fig. 5. The contour plot of the flow field of the wake of the vertical-axis turbine 


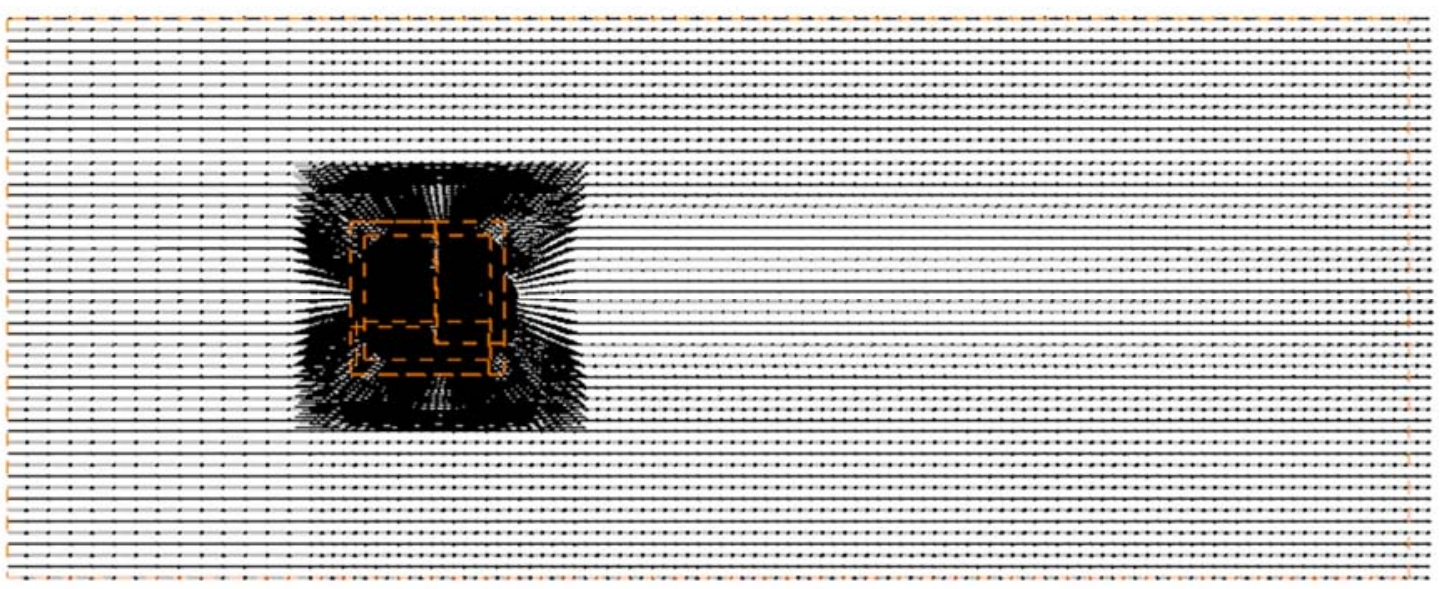

Fig. 6. The vector plot of the flow field of the wake of the vertical-axis turbine

Double Multiple Streamtube model has been conducted to testify the accuracy of CFD numerical simulation. Previous researches agreed on the applicability of Double Multiple Streamtube model [25-27]. According to the research of Brinck et al., the $C_{p}$ of this turbine is 0.192 by calculation [25]. The $C_{p}$ of numerical simulation results is 0.211 , which testified the accuracy of the CFD simulation. Grid independent analysis was conducted to investigate the sensitivity of the grid to the change of $C_{p}$ values. Table1 showed the cases of grid independence tests on the mesh numbers and $C_{p}$ values to reach the grid independent for this mesh. The results find that Case 1 with 2028800 cells has a $\mathrm{Cp}$ value of 0.167 . The $\mathrm{Cp}$ value increases to 0.199 for Case 2 with additional 49248 cells and the $C p$ value increases to 0.211 for Case 3 with additional 102906 cells. After Case 3, the variation of results is insignificant with further increase of cell number. Therefore, Case 3 with 2180954 cells is the selected grid independent case. The velocity data within the wake of a vertical-axis turbine can be obtained to validate the accuracy of the proposed equations.

Table 1

Grid independence tests by comparing different mesh numbers with $C_{p}$ values.

\begin{tabular}{|c|c|c|c|c|}
\hline & Case1 & Case2 & Case3 & Case4 \\
\hline Mesh numbers & 2028800 & 2078048 & 2180954 & 2260760 \\
\hline $\mathrm{C}_{\mathrm{p}}$ & 0.167 & 0.199 & 0.211 & 0.213 \\
\hline Additional cells & - & 49248 & 102906 & 79806 \\
\hline Variation & - & $19.2 \%$ & $6.0 \%$ & $0.9 \%$ \\
\hline
\end{tabular}

\section{Vertical-axis tidal turbine wake model}

Turbine wake is produced downstream when water flows through the turbine. Velocity deficit occurs within the wake due to the energy extraction of the turbine from the flow. However, the water around the turbine wake also affects the velocity within the wake. The kinetic energy of free stream is transferred to the wake by flow mixing along the flow direction. Therefore, velocity within a turbine wake recovers along the flow direction. At the end of a turbine wake, velocity within a turbine wake increases to the 
same velocity as free stream. The phenomenon of velocity recovery becomes more obvious along the flow direction and the recovery prediction is important when arranging the turbines in tandem in a tidal turbine farm.

The concept of efflux velocity was first used in the field of a propeller jet, meaning the maximum time-averaged velocity on the initial propeller plane. As for turbine wake, the efflux velocity is defined as the minimum time-averaged velocity on the initial turbine plane. The minimum velocity will increase along the flow direction. The minimum velocity at each plane can be determined by the efflux velocity. The lateral velocity distribution of each plane can be obtained from the input of the minimum velocity at each plane. In this way, the velocity distribution of the wake of a verticalaxis turbine can be obtained.

Axial momentum theory and Gaussian normal probability function are used. Axial momentum theory is used to obtain the efflux velocity on the initial turbine plane. Gaussian normal probability function is used to describe the lateral distribution of the axial velocity of the turbine wake. By using these methods, the equations to predict efflux velocity and the lateral velocity distribution are proposed in this section.

\subsection{Efflux velocity derivation}

The deduction of the efflux velocity is based on axial momentum theory. The deduction of the efflux velocity of ship propeller and horizontal-axis turbine used actuator disc models to represent them. The rotation plane can be replaced by an actuator disc. The rotation axis coincides with the flow direction for a ship propeller or a horizontal-axis turbine. However, for a vertical-axis turbine, the rotation axis does not coincide with the flow direction. There is no a physical plane for a vertical-axis turbine as it is for a horizontal-axis turbine. In consideration of the difference between the horizontal-axial turbine and the vertical-axis turbine, a vertical-axial turbine should be replaced by a double-actuator disc model, which includes a front disc and a rear disc. A doubleactuator disc model can simplify the model of a vertical-axis turbine and explain the energy conversion. Fig. 7 shows a double-actuator disc model of a vertical-axis turbine along the flow direction. Two actuator discs are set at the two sides of a vertical-axis turbine. 


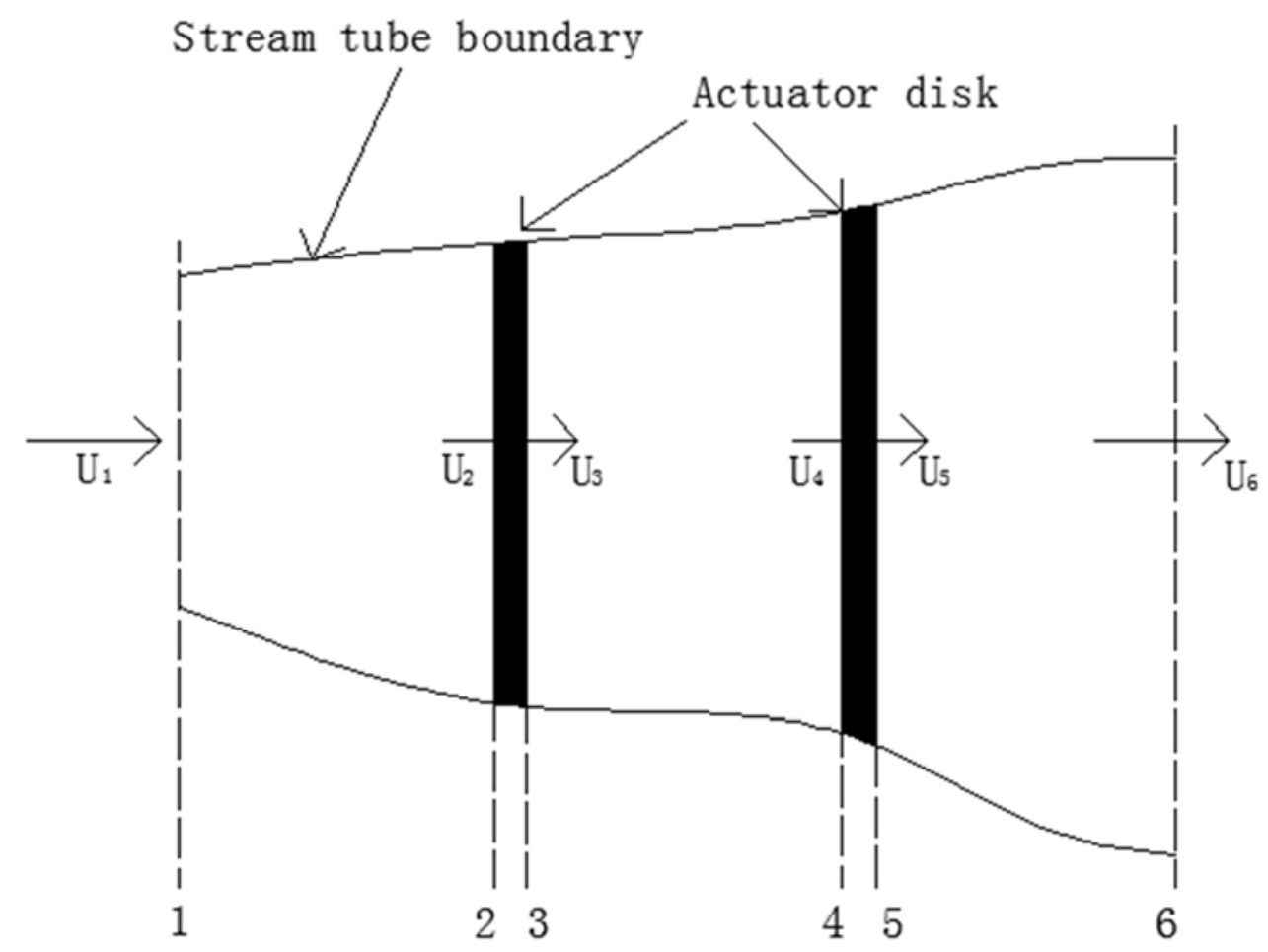

Fig. 7. A double-actuator disc model of a vertical axial turbine

Assume that the Bernoulli function could be applied to the three control volumes, which are on each side of the actuator discs and between them. Eq. (1) shows the relationship between the pressures and velocities upstream of the front disc.

$P_{1}+\frac{1}{2} \rho U_{1}^{2}=P_{2}+\frac{1}{2} \rho U_{2}^{2}$

Eq. (2) shows the relationship between the pressures and velocities between two actuator discs.

$P_{3}+\frac{1}{2} \rho U_{3}^{2}=P_{4}+\frac{1}{2} \rho U_{4}^{2}$

Eq. (3) shows the relationship between the pressures and velocities downstream of the rear disc.

$P_{5}+\frac{1}{2} \rho U_{5}^{2}=P_{6}+\frac{1}{2} \rho U_{6}^{2}$

where $\rho$ is the density of the fluid in $\mathrm{kg} / \mathrm{m}^{3}, \mathrm{U}_{1}, \mathrm{U}_{2}, \mathrm{U}_{3}, \mathrm{U}_{4}, \mathrm{U}_{5}, \mathrm{U}_{6}$ are the axial velocities in $\mathrm{m} / \mathrm{s}$ while $\mathrm{P}_{1}, \mathrm{P}_{2}, \mathrm{P}_{3}, \mathrm{P}_{4}, \mathrm{P}_{5}, \mathrm{P}_{6}$ are the pressures in $\mathrm{Pa}$ at different locations in Fig. 7. 
The thrust is the sum of forces on each actuator disc. Thrusts on the two discs are shown in Eq. (4) and Eq. (5).

$T_{2}=A\left(P_{2}-P_{3}\right)$

$T_{4}=A\left(P_{4}-P_{5}\right)$

where $T_{2}$ and $T_{4}$ are the thrusts in front of and behind the turbine, respectively. $A$ is the area of the actuator disc. $\mathrm{P}_{2}$ and $\mathrm{P}_{3}$ are respective pressures on the two sides of the front disc, $\mathrm{P}_{4}$ and $\mathrm{P}_{5}$ are respective pressures on the two sides of the rear disc. Assume that pressures upstream and downstream are equal $\left(\mathrm{P}_{1}=\mathrm{P}_{6}\right)$ and the velocity keep the same value across the disc $\left(\mathrm{U}_{2}=\mathrm{U}_{3}, \mathrm{U}_{4}=\mathrm{U}_{5}\right)$. By using Eqs. (1)-(5), Eq. (6) is obtained.

$T_{2}+T_{4}=\frac{1}{2} \rho A\left(U_{1}^{2}-U_{6}^{2}\right)$

$\mathrm{U}_{2}, \mathrm{U}_{3}, \mathrm{U}_{4}$ and $\mathrm{U}_{5}$ have not been mentioned according to Eq. (6). It is obvious that $\mathrm{T}_{2}$ and $\mathrm{T}_{4}$ could be merged to one $\mathrm{T}$ which could represent the join forces of $\mathrm{T}_{2}$ and $\mathrm{T}_{4}$. So, the effect of the double-actuator disc model of a vertical axial turbine is equal to the classic actuator disc model. An actuator disc model of a vertical axial turbine is shown in Fig. 8.

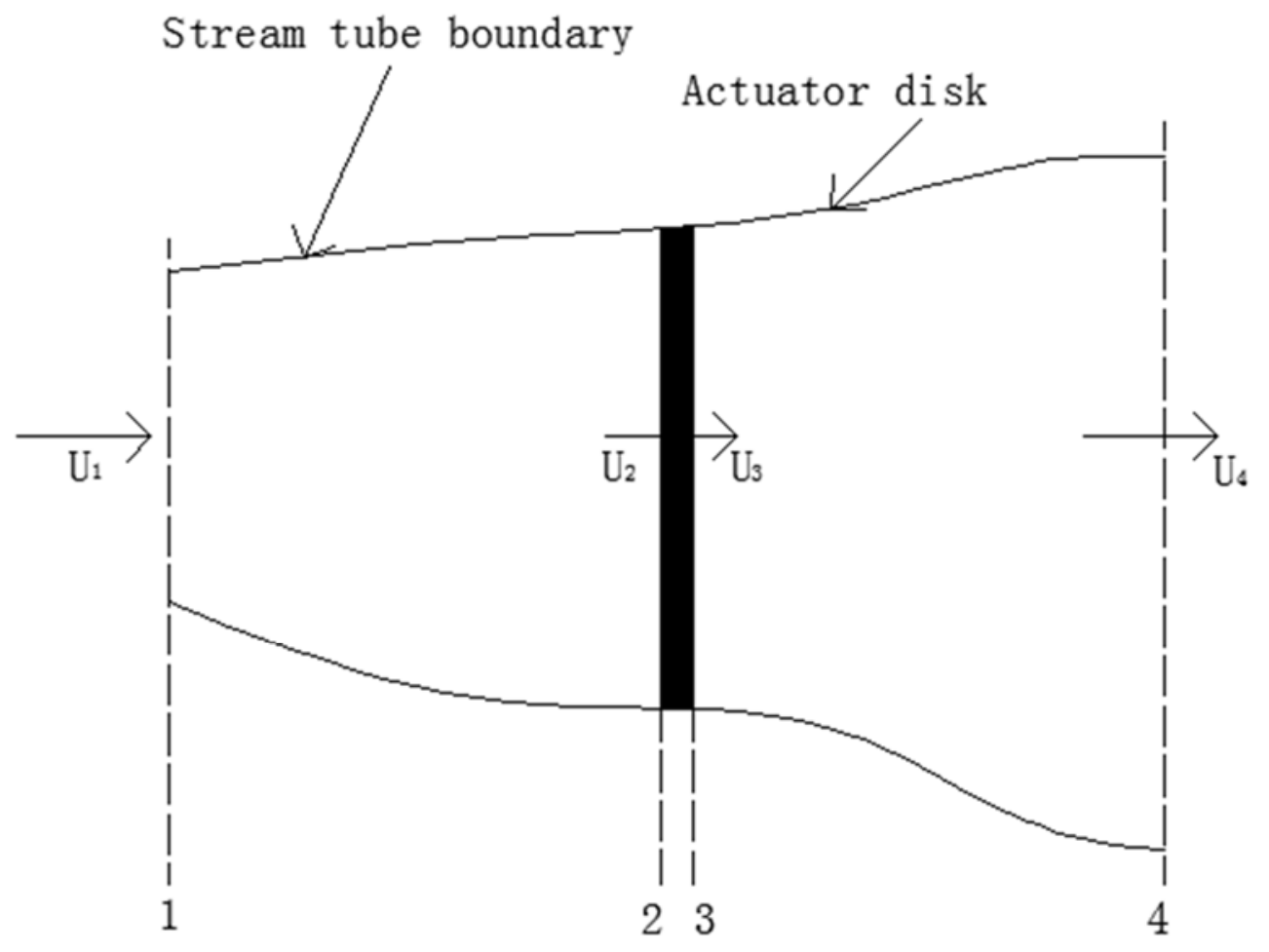

Fig. 8. An actuator disc model of a vertical axial turbine 
Assume that the Bernoulli function could be applied to the two control volumes, which are upstream and downstream of the actuator disc. Eq. (7) shows the relationship between the pressures and velocities upstream.

$P_{1}+\frac{1}{2} \rho U_{1}^{2}=P_{2}+\frac{1}{2} \rho U_{2}^{2}$

Eq. (8) shows the relationship between the pressures and velocities upstream.

$P_{3}+\frac{1}{2} \rho U_{3}^{2}=P_{4}+\frac{1}{2} \rho U_{4}^{2}$

where $\rho$ is the density of the fluid in $\mathrm{kg} / \mathrm{m}^{3}, \mathrm{U}_{1}, \mathrm{U}_{2}, \mathrm{U}_{3}, \mathrm{U}_{4}$ are the axial velocities in $\mathrm{m} / \mathrm{s}$ while $\mathrm{P}_{1}, \mathrm{P}_{2}, \mathrm{P}_{3}, \mathrm{P}_{4}$ are the pressures in $\mathrm{Pa}$ at each location in Fig. 6.

The thrust on the actuator disc is shown in Eq. (9).

$T=A\left(P_{2}-P_{3}\right)$

where $\mathrm{T}$ is the thrust on the actuator disc, $\mathrm{A}$ is the area of the actuator disc. Assume that pressures upstream and downstream are equal $\left(\mathrm{P}_{1}=\mathrm{P}_{4}\right)$ and the velocity keep the same value across the disc $\left(\mathrm{U}_{2}=\mathrm{U}_{3}\right)$. Eq. (10) is obtained by using Eq. (7)-(9).

$T=\frac{1}{2} \rho A\left(U_{1}^{2}-U_{4}^{2}\right)$

As a result of dimensional analysis, similar to the thrust on the propeller, the thrust $\mathrm{T}$ could be written as Eq. (11) considering density, velocity and the area of the disc.

$T=\frac{1}{2} \rho \mathrm{A} U^{2} C_{T}$

where $\mathrm{C}_{\mathrm{T}}$ is the thrust coefficient, $\rho$ is the density of fluid in $\mathrm{kg} / \mathrm{m}^{3}, \mathrm{~A}$ is the area of the actuator disc, $U$ is the velocity of the flowing water, which could be substituted to $U_{1}$, $\mathrm{T}$ is the thrust in Newtons.

Equating Eq. (10)-(11), Eq. (12) is obtained by taking the efflux velocity as $\mathrm{V}_{0}$ and the free stream velocity as $V_{\infty}$.

$V_{0}=V_{\infty} \sqrt{1-C_{T}}$

Therefore, the equation to predict the efflux velocity has been proposed. The inputs are 
the velocity of the flowing water $\mathrm{V}_{0}$ and the thrust coefficient $\mathrm{C}_{\mathrm{T}}$.

\subsection{Lateral velocity distribution within vertical-axis turbine wake}

Previous studies show that the axial velocity distribution of a horizontal-axis turbine wake has two valley values in the zone of flow establishment [14]. Two valley values of the axial velocity move to the middle gradually along the flow direction. At the edge of the zone of flow establishment, two valley values of the axial velocity turn to one valley value at the middle. In the zone of established flow, the velocity of the turbine wake increases and the valley value disappears gradually.

As for the wake of a vertical-axis turbine, there is one valley value which is not at the middle of the lateral section. However, the position of the valley value would not move to the middle along the axial direction, it would keep its position until the valley value disappears which means that the velocity of the wake equals to the free stream velocity. It is because of the rotational feature of the vertical-axis turbine which is different from it of the horizontal-axis turbine.

To describe the lateral velocity distribution on each plane along the axial direction, Gaussian normal probability function is used. Eq. (13) was proposed by Albertson et al. (1950) to predict the lateral velocity distribution of a propeller [15].

$\frac{V_{x, r}}{V_{\max }}=e^{-\left(\frac{r^{2}}{2 \sigma^{2}}\right)}$

where $V_{x, r}$ is the lateral distribution velocity in $\mathrm{m} / \mathrm{s}, \mathrm{x}$ is the axial distance in meters, $\mathrm{r}$ is the radial distance in meters and $V_{\max }$ is the maximum lateral distribution velocity of the plane in $\mathrm{m} / \mathrm{s}$.

The method used to predict the lateral velocity distribution of a propeller can be applied to predict the lateral velocity distribution of a tidal-current turbine. Tidal turbine wake's lateral velocity distribution equation can be derived by referring to the work of Albertson et al. (1950) [15]. In spite of the position of the valley value, the lateral velocity distribution can be predicted by Eq. (14).

$V_{x, r}=V_{\infty}-\left(V_{\infty}-V_{\min }\right) e^{-\left(\frac{r^{2}}{2 \sigma^{2}}\right)}$

where $V_{x, r}$ is the lateral distribution velocity in $\mathrm{m} / \mathrm{s}, \mathrm{x}$ is the axial distance in meters, $\mathrm{r}$ is the radial distance in meters, $V_{\infty}$ is the velocity of free stream in $\mathrm{m} / \mathrm{s}, V_{\min }$ is the minimum velocity of the section in $\mathrm{m} / \mathrm{s}$ and $\sigma$ is the standard deviation of velocity at the lateral section.

Taking the position of the valley value into account and substituting $C D_{t}$ for $\sigma$, the lateral velocity distribution can be predicted by Eq. (15). 
$V_{x, r}=V_{\infty}-\left(V_{\infty}-V_{\min }\right) e^{-\frac{\left[r+B D_{t}\right]^{2}}{2\left(C D_{t}\right)^{2}}}$

where $D_{t}$ is the diameter of the vertical-axis turbine, $\mathrm{B} D_{t}$ is the deviation of the valley value of velocity at each section on the flow direction, $C D_{t}$ is the standard deviation of velocity at each section along the flow direction. In the wake of a verticalaxis turbine, the velocity deficit area seems not expand at different sections downstream like it is of a horizontal-axis. The wake of a vertical-axis turbine has its own features. So the standard deviation of velocity keeps the same. The deviation of the valley value of velocity also keeps its position.

Eq. (15) can be used to predict the lateral velocity distribution at different locations in the downstream direction of a vertical-axis turbine wake. Fig. 9 shows the lateral velocity distribution in the wake.

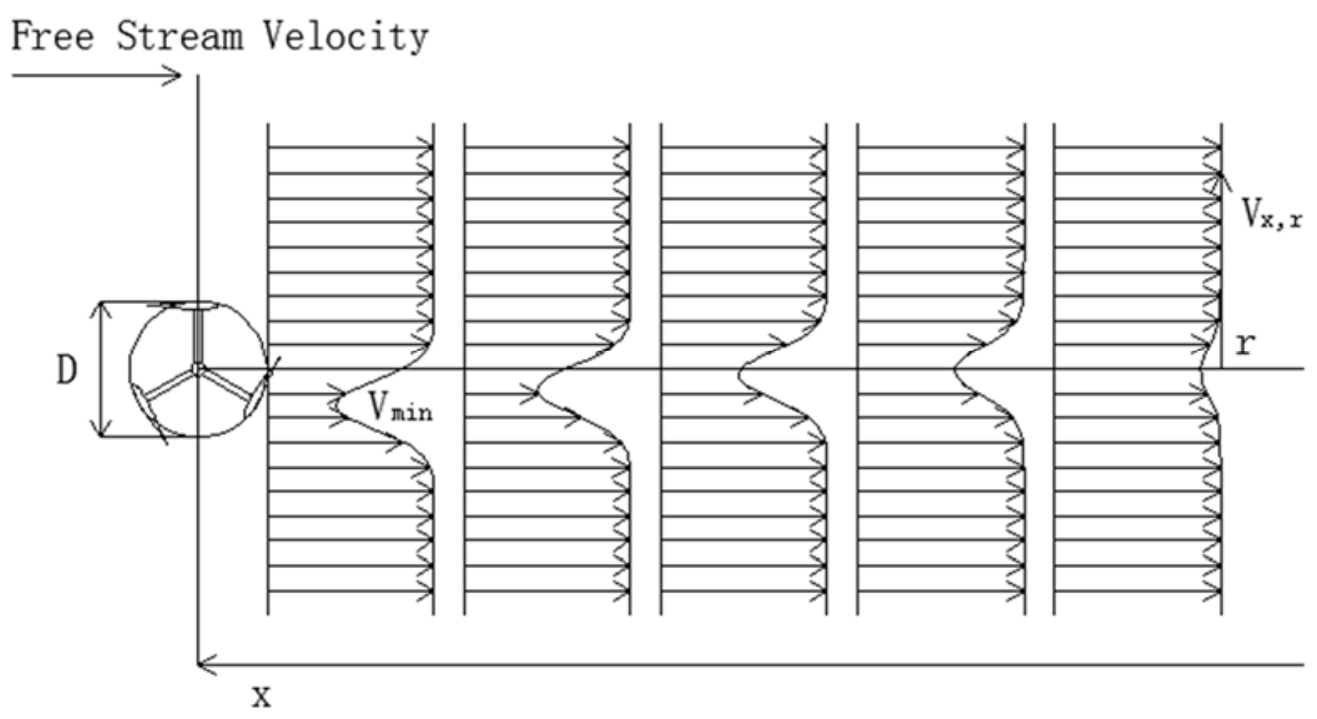

Fig. 9. The wake profile along the downstream direction by using the lateral velocity distribution equation

\section{Results and Discussions}

The accuracy of the proposed equations should be verified. Eqs. (12) and (15) are used to predict the efflux velocity and lateral velocity distribution in the axial direction. Previous results of researchers would be compared with the theoretical results derived from the equations. The published works are selected to testify the equations. The accuracy of the proposed equations is determined by the discrepancies between the results.

\subsection{Proposed wake model and the previous experimental measurements}

The validation of the efflux velocity equation has been done based on the Dai and Lam's 
experimental measurements. Dai and Lam investigate the maximum power coefficient as a function of solidity and flow velocity [28]. Physical tests were carried out on a squirrel cage straight-bladed Darrieus model turbine. The blade length (height of turbine) is $700 \mathrm{~mm}$ and the turbine radius is $450 \mathrm{~mm}$. The free stream velocities and power coefficients shown in Table 2 are used to testify the equation.

Table 2

Power coefficients under different flow velocities.

\begin{tabular}{|l|l|}
\hline \multicolumn{1}{|c|}{$\mathrm{V}_{\infty}$} & \multicolumn{1}{c|}{$\mathrm{C}_{\mathrm{p}}$} \\
\hline 1.62 & 0.231 \\
\hline 1.41 & 0.223 \\
\hline 1.22 & 0.211 \\
\hline 0.99 & 0.205 \\
\hline
\end{tabular}

The efflux velocities are obtained by using Eq. (16).

$V_{0}=V_{\infty} \sqrt{1-C_{p}}$

The efflux velocities are calculated from Table 2, the thrust coefficient $\mathrm{C}_{\mathrm{T}}$ is determined by using Eq. (12) with the flow velocity $1.62 \mathrm{~m} / \mathrm{s}$ and the efflux velocity $1.42 \mathrm{~m} / \mathrm{s}$. The result of $\mathrm{C}_{\mathrm{T}}$ is 0.231 . Then the theoretical efflux velocities are calculated by using the input of $\mathrm{C}_{\mathrm{T}}=0.231$. The results of comparison are shown in Table 3 .

Table 3. Comparison of the efflux velocities calculated by experimental results and theoretical efflux velocities with different flow velocities

\begin{tabular}{|l|l|l|l|}
\hline Free stream $\mathrm{V}_{\infty}$ & $\begin{array}{c}\mathrm{V}_{0} \text { calculated by } \\
\text { experimental } \\
\text { results }(\mathrm{m} / \mathrm{s})\end{array}$ & $\begin{array}{c}\text { Theoretical } \mathrm{V}_{0} \\
(\mathrm{~m} / \mathrm{s})\end{array}$ & \multicolumn{1}{|l|}{ Variation $(\%)$} \\
\hline 1.62 & 1.42 & 1.42 & 0 \\
\hline 1.41 & 1.24 & 1.23 & 0.81 \\
\hline 1.22 & 1.08 & 1.07 & 1.93 \\
\hline 0.99 & 0.88 & 0.87 & 1.13 \\
\hline
\end{tabular}

From the Comparison of efflux velocities calculated by the experimental results and theoretical efflux velocities, the variations in range of $0-1.13 \%$ was found with a maximum variation of $1.13 \%$ at $0.99 \mathrm{~m} / \mathrm{s}$ free stream, as shown in Table 3 . The variations maybe caused by the limitation of the axial momentum theory and some factors such as the shape of blades, thrust, rotational parameters have not been considered in the derivation. These parameters should be considered in the future studies. 


\subsection{CFD corrections for lateral velocity distribution}

Computational Fluid Dynamics (CFD) is an effective tool to solve engineering problems related to fluids. The CFD can give the details of the flow field and the performance of the tidal-current turbine. Referring to the Guo et al.'s numerical simulation results, the validation of the lateral velocity distribution equation has been done. Guo et al. investigated the velocity at increasing distance downstream for a vertical-axis turbine [29]. The diameter of the turbine model is $900 \mathrm{~mm}$, the length of the blade chord is $132.75 \mathrm{~mm}$, the aerofoil is NACA0025, and the velocity of the free stream is $1.62 \mathrm{~m} / \mathrm{s}$. As shown in Fig. 10, the velocity downstream at $\mathrm{x}=\mathrm{D}, \mathrm{x}=9 \mathrm{D}$ and $\mathrm{x}=20 \mathrm{D}$ indicates the wake development of a vertical-axis turbine. The valley value of velocity occurs at $\mathrm{r}=0.176 \mathrm{D}$ when $\mathrm{x}=9 \mathrm{D}$. So $\mathrm{B}=0.176, \mathrm{C}=0.4$ are obtained by calculating. As above mentioned, the free flow velocity $V_{\infty}=1.62 \mathrm{~m} / \mathrm{s}$ and the diameter of the turbine $\mathrm{D}=0.9 \mathrm{~m}$. The minimum mean velocity $V_{\min }$ is exacted from the numerical results shown in Fig.10. According to the lateral velocity distribution, the Eq. (15) can be replaced for Eq. (17).

$V_{x, r}=V_{\infty}-\left(V_{\infty}-V_{\text {min }}\right) e^{-\frac{\left[r-0.176 D_{t}\right]^{2}}{2(0.4 x)^{2}}}$

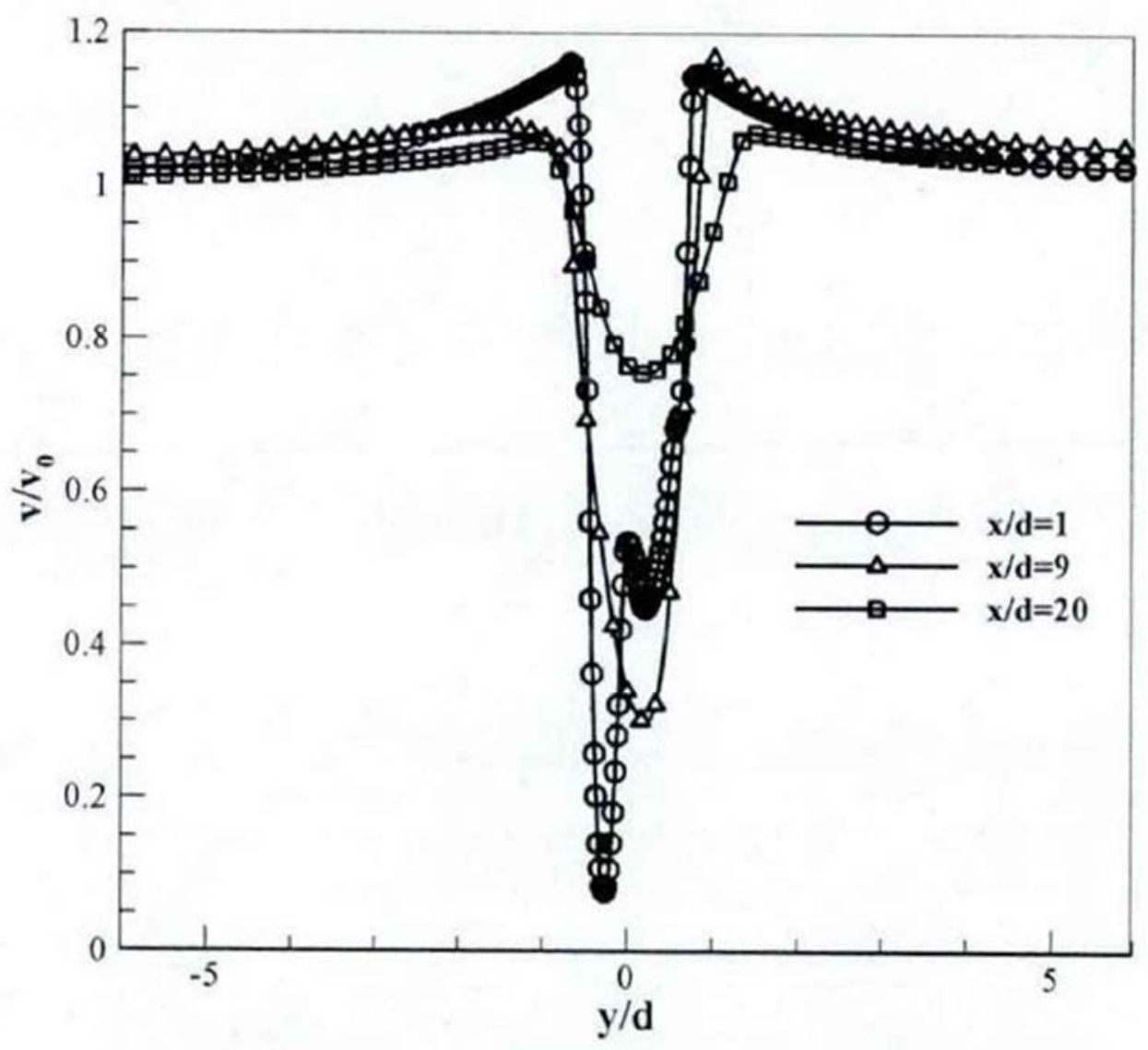

Fig. 10. The velocity at increasing distance downstream for a vertical-axis turbine (Guo 2014) 


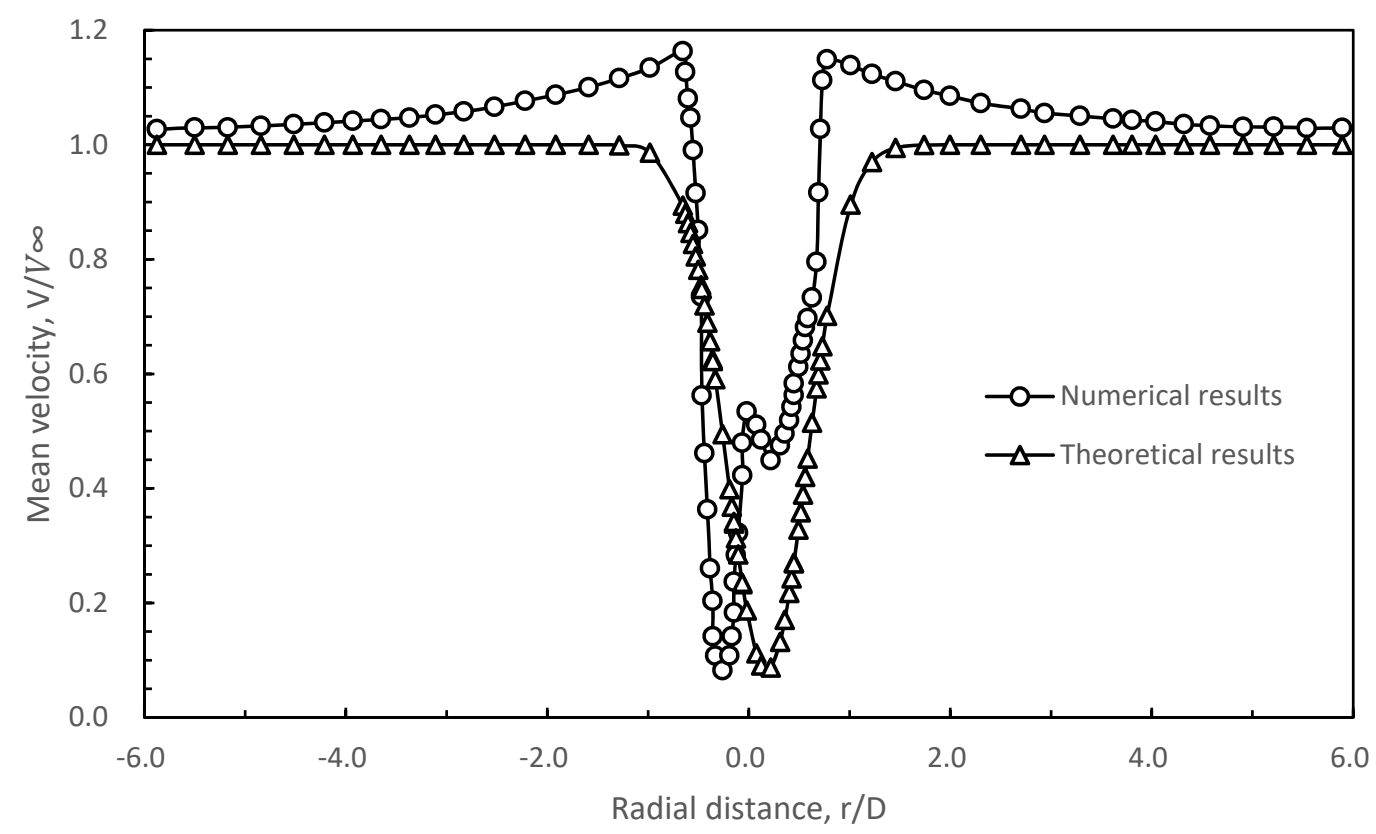

b

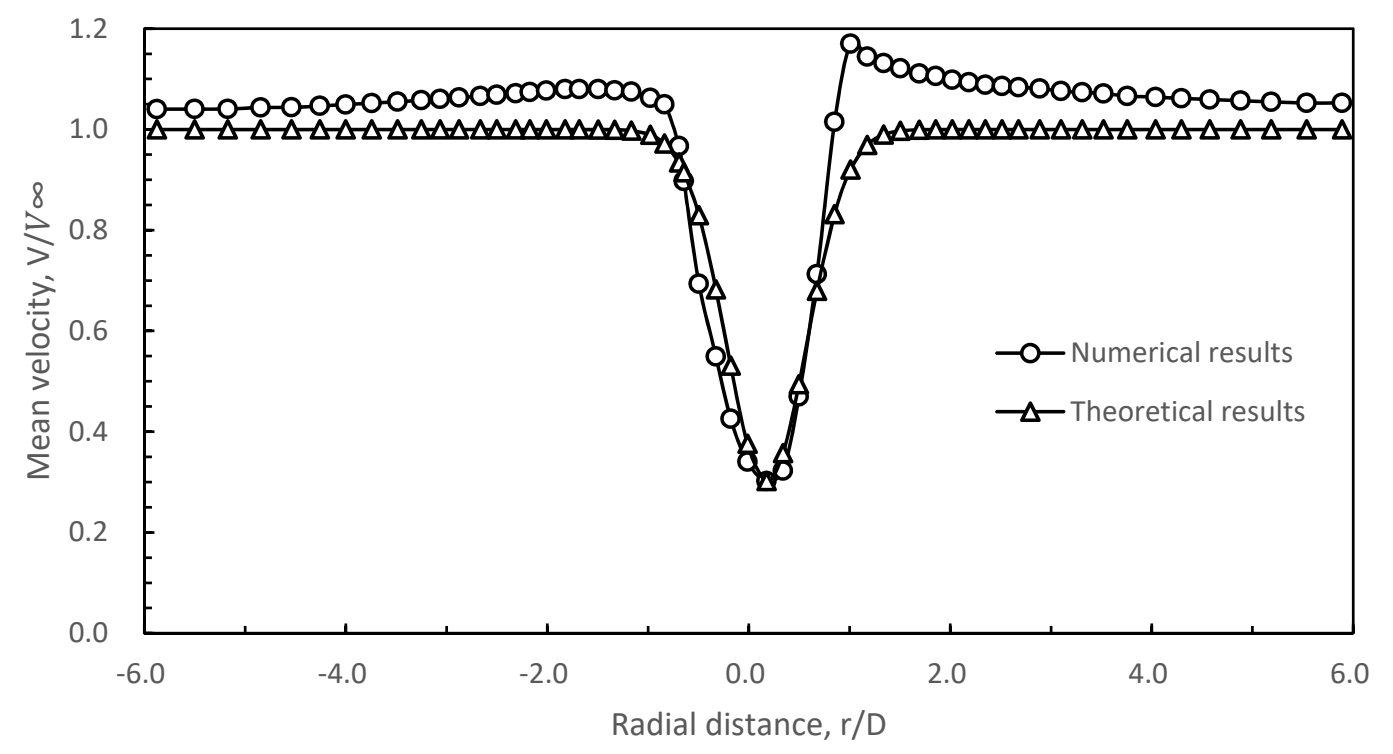

Fig.11. Comparison of the lateral velocity distribution between the numerical and theoretical results: (a) $\mathrm{x} / \mathrm{D}=1.0$; (b) $\mathrm{x} / \mathrm{D}=9.0$.

Fig.11 shows the lateral velocity distribution profiles of the numerical and theoretical results at $1 \mathrm{D}$ and $9 \mathrm{D}$ downstream. At $1 \mathrm{D}$ downstream, the theoretical results at the radial distance from $\mathrm{r} / \mathrm{D}=-0.5$ to -0.3 and from $\mathrm{r} / \mathrm{D}=0.6$ to 0.8 fit the numerical results well while discrepancies occur at radial distance from $\mathrm{r} / \mathrm{D}=-0.3$ to 0.6 , which is due to the turbulence of the un-fully developed flow field. At 9D downstream, the numerical and theoretical results fit well from $r / D=-0.7$ to 0.9 . The discrepancies which occur at -6.0 
to -0.7 and 0.8 to 6.0 at both $1 \mathrm{D}$ and $9 \mathrm{D}$ downstream are due to the blockage effect of the turbine. At 1D downstream, the largest variation in the theoretical mean stream velocity is $35 \%$. At 9D downstream, the largest variation in the theoretical mean stream velocity is $21.4 \%$. The blockage effect is not considered in the theoretical equations. The kinetic energy of the region of velocity increasing will be transferred to the velocity deficit region along the flow.

The results of CFD numerical simulation of a vertical-axis turbine wake in Chapter 2 are used to validate Eq. (15). The velocity at increasing distance downstream for a vertical-axis turbine could be obtained. As shown in Fig. 12, the lateral velocity distribution downstream at $x=1 D, x=2 D, x=3 D, x=4 D$ and $x=5 D$ indicates the wake development of a vertical-axis turbine. As above mentioned, the free flow velocity $V_{\infty}=2 \mathrm{~m} / \mathrm{s}$ and $\mathrm{D}=1 \mathrm{~m} . \mathrm{B}=0.43, \mathrm{C}=0.2$ are obtained by calculating. The minimum mean velocity $V_{\min }$ is exacted from the numerical results shown in Fig.12. Thus according to the lateral velocity distribution, the Eq. (15) can be replaced by Eq. (18).

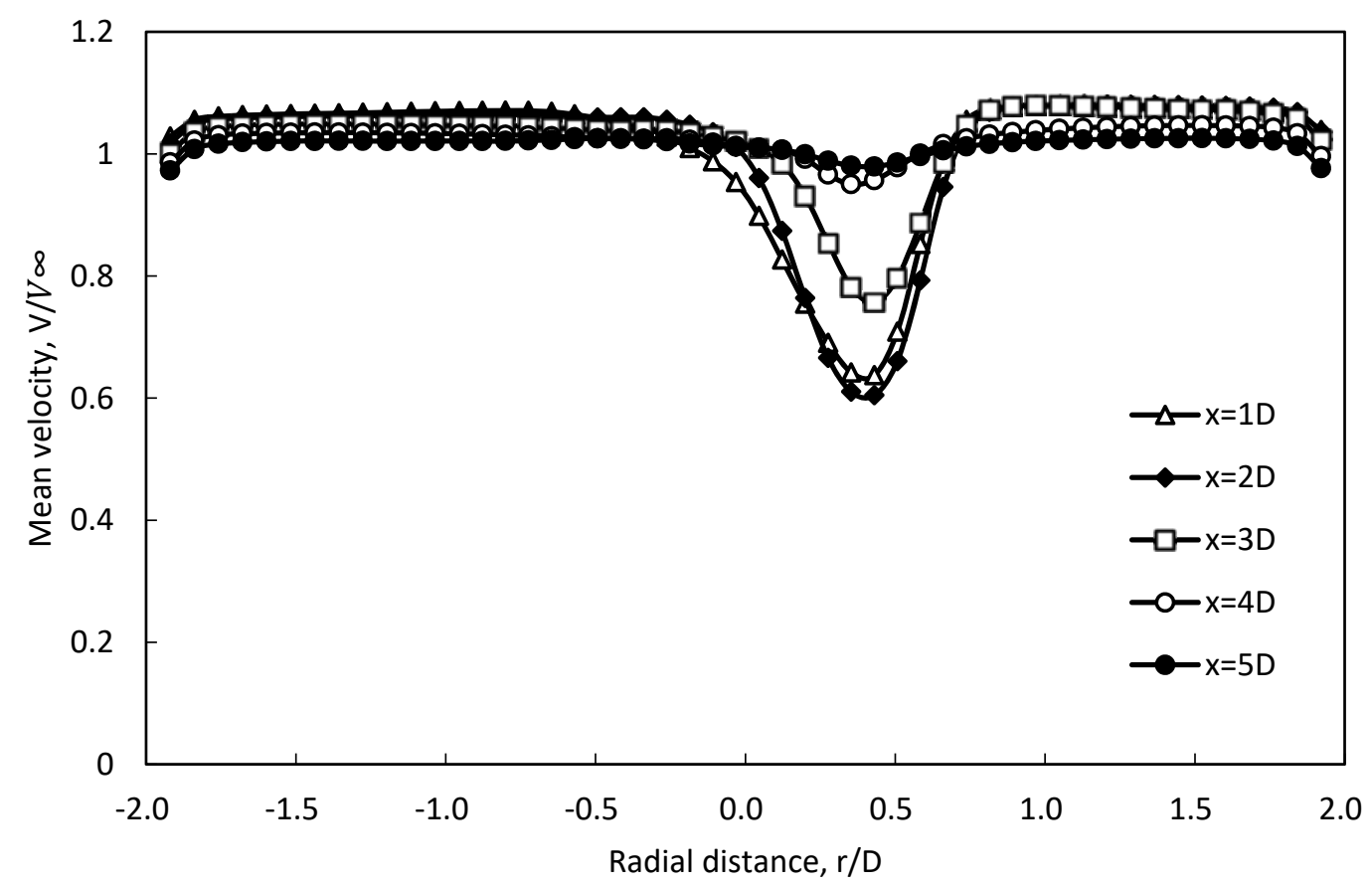

Fig. 12. The velocity at increasing distance downstream for a vertical-axis turbine

$V_{x, r}=V_{\infty}-\left(V_{\infty}-V_{\min }\right) e^{-\frac{\left[r-0.43 D_{t}\right]^{2}}{2\left(0.2 D_{t}\right)^{2}}}$

Fig.13 shows the lateral velocity distribution profiles of the numerical and theoretical results at $1 \mathrm{D}, 2 \mathrm{D}, 3 \mathrm{D}, 4 \mathrm{D}$ and $5 \mathrm{D}$ downstream. At $\mathrm{x} / \mathrm{D}=1.0$, the numerical and theoretical results fit well from $r / D=-0.3$ to 0.4 . The discrepancies which occur from $\mathrm{r} / \mathrm{D}=-2.0$ to -0.3 and from $\mathrm{r} / \mathrm{D}=0.4$ to 2.0 are due to the blockage effect of the turbine. At this region, the largest variation in the theoretical mean stream velocity is $17.78 \%$. 
At $x / D=2.0$, the numerical and theoretical results fit well from $r / D=0.0$ to 0.5 . The discrepancies which occur at -2.0 to 0.0 and 0.5 to 2.0 are due to the blockage effect of the turbine. At this region, the largest variation in the theoretical mean stream velocity is $15.82 \%$.
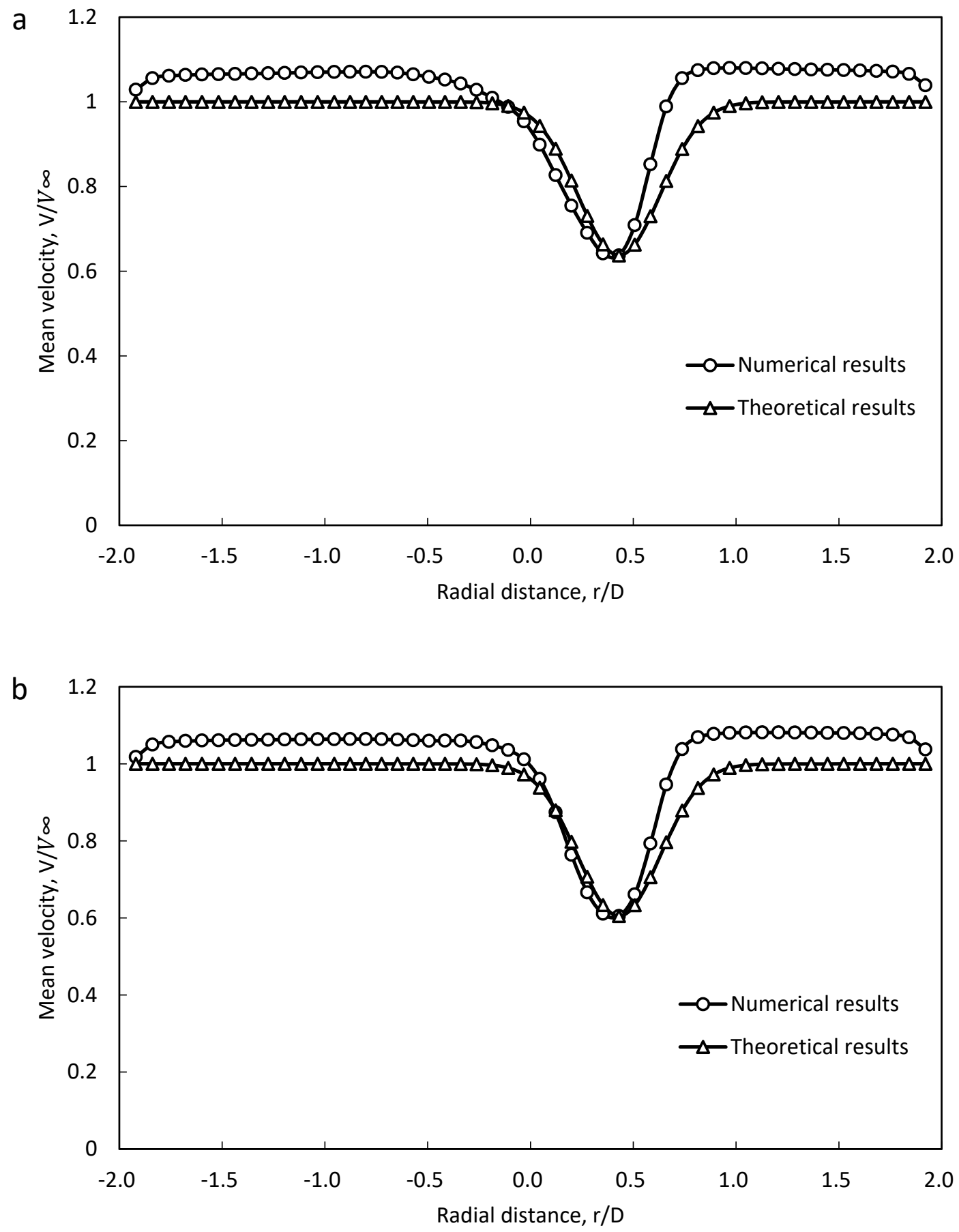

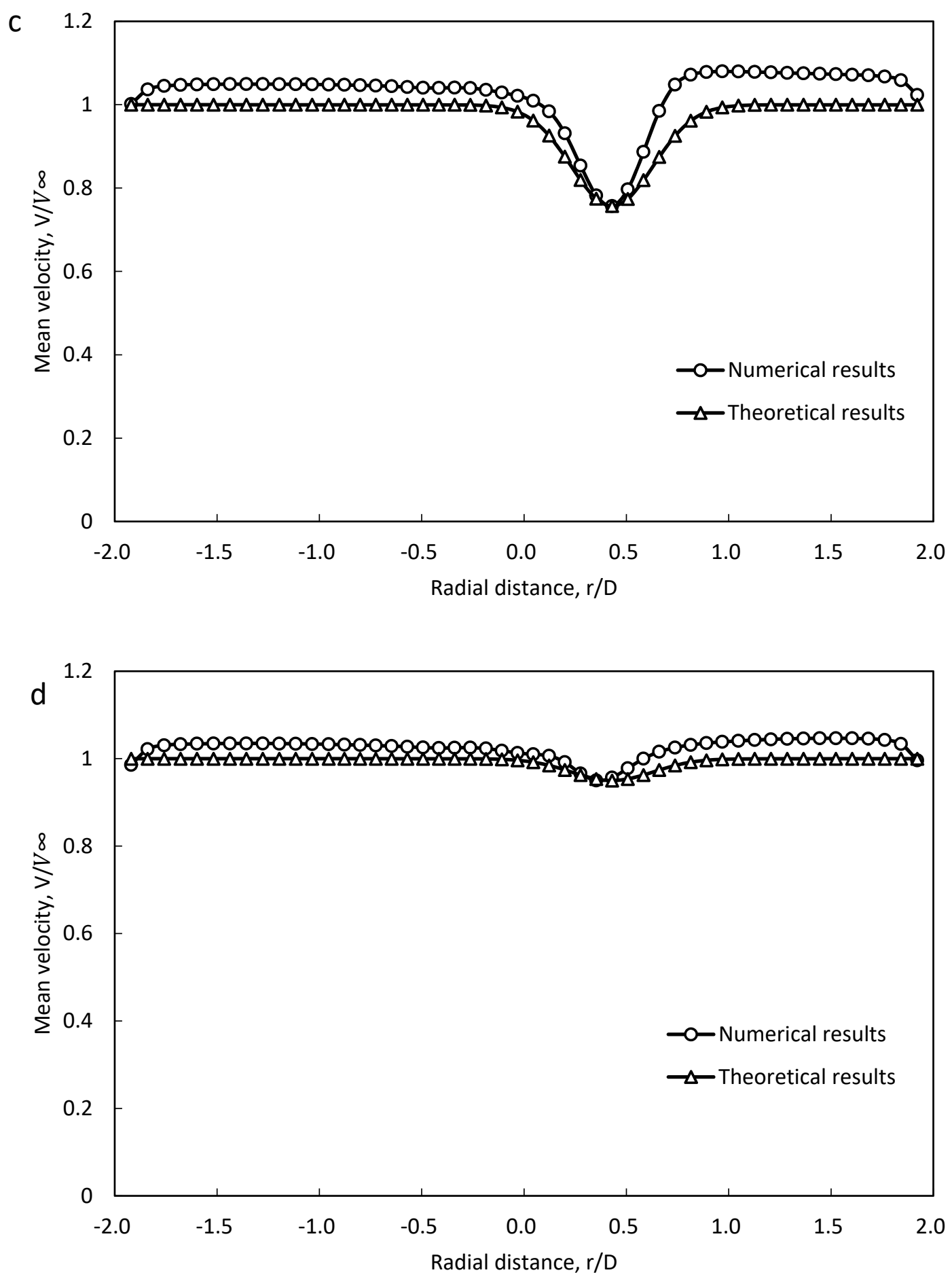


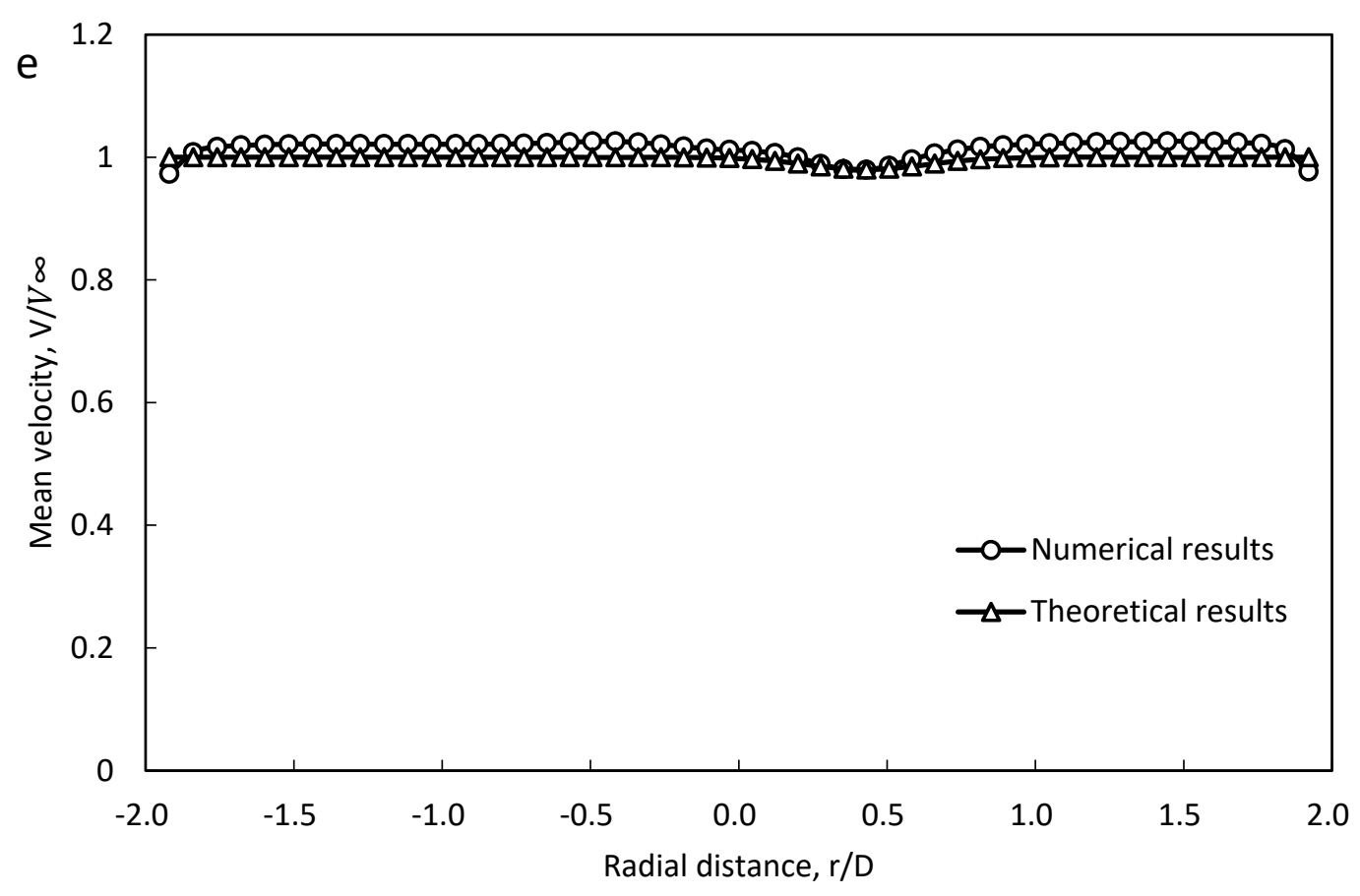

Fig.13. Comparison of the lateral velocity distribution between the numerical and theoretical results: (a) $\mathrm{x} / \mathrm{D}=1.0 ;$ (b) $\mathrm{x} / \mathrm{D}=2.0$; (c) $\mathrm{x} / \mathrm{D}=3.0$; (d) $\mathrm{x} / \mathrm{D}=4.0 ;$ (e) $\mathrm{x} / \mathrm{D}=5.0$.

At $x / D=3.0$, the numerical and theoretical results fit well from $r / D=0.3$ to 0.5 . The discrepancies which occur at -2.0 to 0.3 and from 0.5 to 2.0 are due to the blockage effect of the turbine. At this region, the largest variation in the theoretical mean stream velocity is $11.73 \%$.

At $x / D=4.0$, the numerical and theoretical results fit well from $r / D=-2.0$ to 0.5 . The discrepancy which occurs from $\mathrm{r} / \mathrm{D}=0.5$ to 2.0 are due to the blockage effect of the turbine. At this region, the largest variation in the theoretical mean stream velocity is $4.49 \%$.

And at $\mathrm{x} / \mathrm{D}=5.0$, the numerical and theoretical results fit well from $\mathrm{r} / \mathrm{D}=-2.0$ to 2.0 . The recovery of velocity deficit has almost done. At this region, the largest variation in the theoretical mean stream velocity is $2.77 \%$.

It is obvious that the curves of the numerical and theoretical results have the same tendency. Most of the theoretical results fit well to the numerical results. However, there are discrepancies out of the area of velocity deficit. It is due to the blockage effect of the turbine. When fluid flows by a structure, the blockage of the structure causes the extrusion of the fluid around the structure which pushes fluid away from the structure. Therefore the fluid at the two sides of the structure is accelerated. Generally, the theoretical equation to predict the lateral velocity distribution of a vertical-axis turbine can be used to provide references for engineers. 


\subsection{Vertical-axis-turbine and horizontal-axis-turbine wake models}

Equations proposed by Lam et al. give symmetric curves of the lateral velocity distribution of a horizontal-axis turbine. However, because of the rotation feature which is different from of the horizontal-axis turbine, a deviation occurs at the area of velocity deficit of a vertical-axis turbine. Fig. 14 shows the comparison of the lateral velocity distribution between the wake of a horizontal-axis turbine and a vertical-axis turbine. Data is from Lam et al. [14].

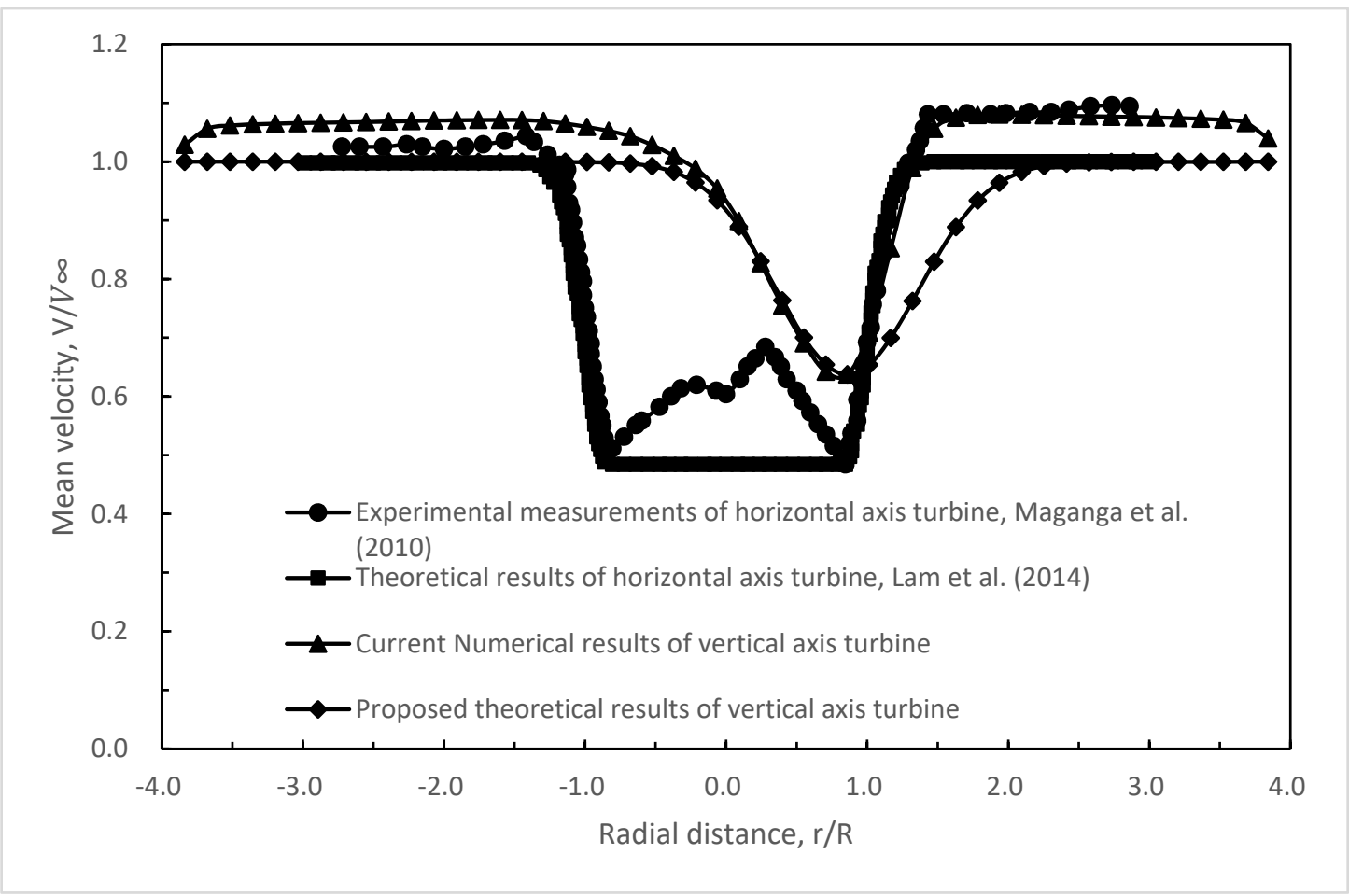

Fig.14. Comparison of the lateral velocity distribution between the wake at $x=1 D$ of a horizontalaxis turbine and a vertical-axis turbine.

The position of the efflux velocity is different for the wakes from a horizontal-axis turbine and a vertical-axis turbine. It is obvious that a deviation occurs at the position of efflux velocity in the wake of a vertical-axis turbine, whereas the position of efflux velocity of horizontal-axis turbine is located at the central axis. As for the vertical-axis turbine, the valley value of the axial velocity keeps its position from the initial plane to the end of the flow field of velocity deficit while the velocity deficit recovers along the downstream direction. However, the lateral velocity distribution curves of the wake of a horizontal-axis turbine are approximately axisymmetric. The position of valley value at each side of the axis on the flow direction tends to move to the middle as the flow develops. Two valley values turn to one at the middle position when it comes to the zone of established flow. The recovery of the velocity deficit of a horizontal-axis turbine is all along the flow direction. The wake structure is the biggest difference between the wake of a horizontal-axis turbine and a vertical-axis turbine. The rotation axis of a horizontal-axis turbine is on the same direction of the free stream, while the rotation 
axis of a vertical-axis turbine is perpendicular to the direction of the free stream. The deviation of the valley value of axial velocity occurs at the wake of a vertical-axis turbine, while the lateral velocity distribution curves of the wake of a horizontal-axis turbine are approximately axisymmetric. In addition, the shape of blades of a horizontal-axis turbine is more complex, while the shape of blades of a vertical-axis turbine remains unchanged along the direction of the $\mathrm{Z}$ axis. Therefore there are two valley values in the zone of flow establishment of the wake of a horizontal-axis turbine rather than a vertical-axis turbine. Thus, the proposal of equations to predict the efflux velocity and the lateral velocity distribution of a vertical-axis turbine makes the difference more clear.

\subsection{Schematic presentation of vertical-axis-turbine wake model}

Turbine wake consists of the near wake and the far wake, in which the near wake is affected significantly by the shape of turbine while the far wake is not. The schematic diagram is shown in Fig.15.

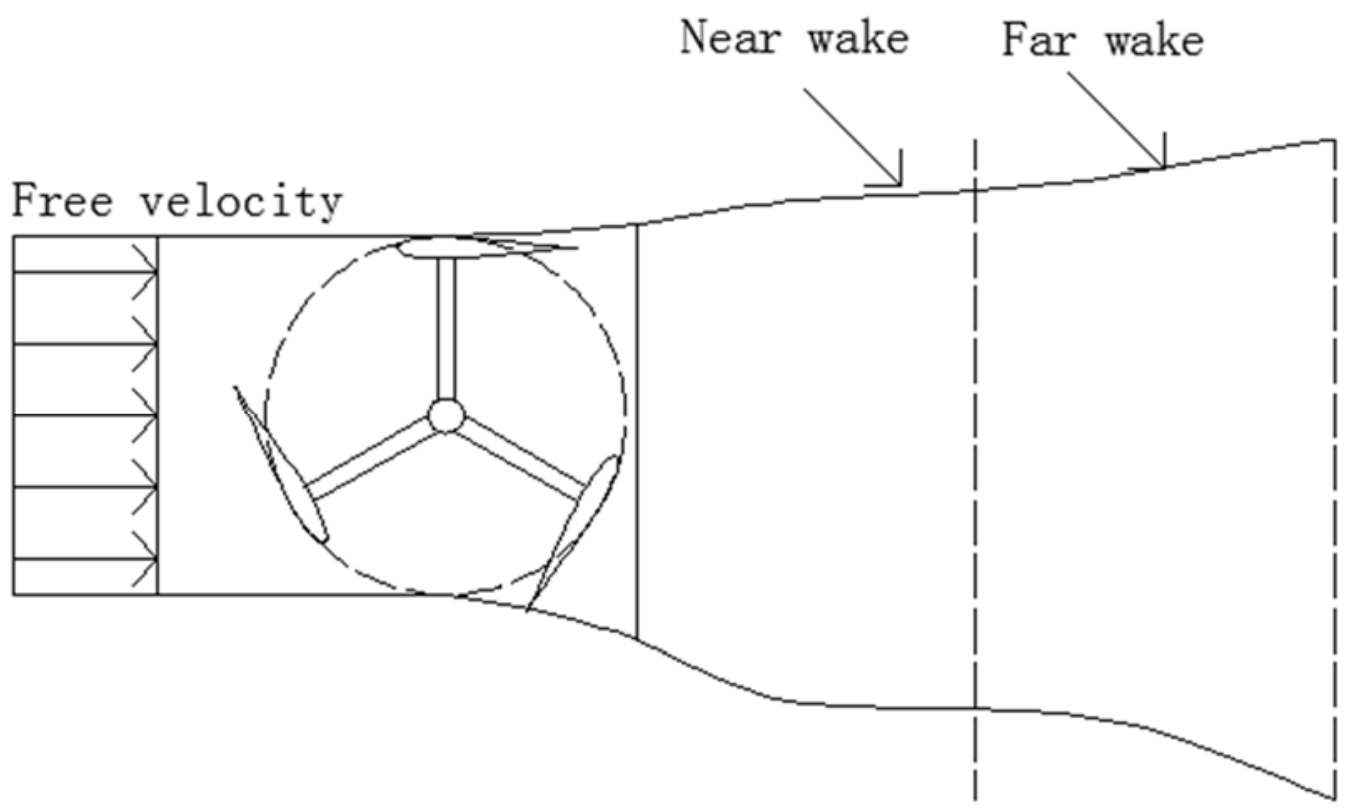

Fig. 15. A schematic diagram of a vertical axial turbine wake

The kinetic energy of free stream will be transferred to the wake by the flow mixing. Velocity within a turbine wake will recover along the flow. The turbine wake also expands along the flow. As for a horizontal-axis turbine, in the zone of flow establishment, the lateral velocity distribution at a plane has two valley values and in the zone of established flow, the lateral velocity distribution at a plane has only one valley value at the centre of the flow direction. As for a vertical-axis turbine, in the near wake, there is some turbulence due to the insufficient development of flow field and in the far wake, the lateral velocity distribution at a plane has only one valley value which 
moves to the center along the flow direction.

\section{Conclusions}

Equations to predict the efflux velocity and the lateral velocity distribution of a verticalaxis turbine could make up for the deficiency of the equations for a horizontal-axis turbine. It is obvious that there are some differences between a vertical-axis turbine and a horizontal-axis turbine. By using these equations, engineers can predict the velocity within the wake of a vertical-axis tidal turbine. The contributions of this research are:

1. The efflux velocity equation of a vertical-axis turbine wake was proposed. It could be used to predict the velocity deficit along the downstream direction of a verticalaxis turbine wake. The recommended $C_{T}$ is 0.231 . The maximum variation is $1.13 \%$ at $0.99 \mathrm{~m} / \mathrm{s}$ free stream by comparing the proposed theoretical works and Dai and Lam's experimental measurements [28].

$$
V_{0}=V_{\infty} \sqrt{1-C_{T}}
$$

2. The lateral velocity distribution equation of a vertical-axis turbine wake is proposed. It could be used to predict the velocity distribution of different planes along the downstream direction of a vertical-axis turbine wake. The parameters can be substituted for different rotation characteristics.

$$
V_{x, r}=V_{\infty}-\left(V_{\infty}-V_{\min }\right) e^{-\frac{\left[r+0.43 D_{t}\right]^{2}}{2\left(0.2 D_{t}\right)^{2}}}
$$

3. The position of the efflux velocity is determined by the shape of blades and the rotation characteristics. The position is generally predicted using Equation (21).

$$
r=-0.4 D_{t}
$$

These equations are based on the axial momentum theory and Gaussian normal probability function. Equations to predict the lateral velocity distribution do not consider the influence of the support structure of turbine. The wake produced by the support structure should be considered especially near the turbine. It is one of topics suggested to be discussed in the future. Beyond that, the effect of the hub, the shape of the blades of turbine, the rotational features and the turbulence of flowing water should also be considered. The possibility of a more realistic condition is proposed. Future work will consider more influential factors.

\section{Acknowledgement}

The current research was supported by the fund of Tianjin Natural Science Foundation (18JCYBJC21900) and Beiyang Scholar Foundation, People's Republic of China. The 
authors wish to extend their gratitude to Queen's University Belfast, University of Plymouth, University of Oxford, Dalian University of Technology, University of Malaya, Universiti Teknologi Malaysia and Southern University College for the previous supports.

\section{References}

[1] von Jouanne A, Brekken TKA. Ocean and Geothermal Energy Systems. PROCEEDINGS OF THE IEEE 2017; 105(11):2147-2165.

[2] Chang YC, Wang NN. Legal system for the development of marine renewable energy in China. RENEWABLE \& SUSTAINABLE ENERGY REVIEWS 2017; 75:192-196.

[3] Uihlein A, Magagna D. Wave and tidal current energy - A review of the current state of research beyond technology. RENEWABLE \& SUSTAINABLE ENERGY REVIEWS 2016; 58:1070-1081.

[4] Wei XS, Huang B, Liu P, Kanemoto T, Wang LQ. Experimental investigation into the effects of blade pitch angle and axial distance on the performance of a counterrotating tidal turbine. OCEAN ENGINEERING 2015; 110:78-88.

[5] Liu J, Lin H, Purimitl SR, Dass M. The effects of blade twist and nacelle shape on the performance of horizontal axis tidal current turbines. APPLIED OCEAN RESEARCH 2017; 64:58-69.

[6] Wang K, Sun K, Sheng QH, Zhang L, Wang SQ T. The effects of yawing motion with different frequencies on the hydrodynamic performance of floating vertical-axis tidal current turbines. APPLIED OCEAN RESEARCH 2016; 59:224-235.

[7] Liu PF, Bose N, Frost R, Macfarlane G, Lilienthal T, Penesis I. Model testing and performance comparison of plastic and metal tidal turbine rotors. APPLIED OCEAN RESEARCH 2015; 53:116-124.

[8] Atcheson M, MacKinnon P, Elsaesser B. A large scale model experimental study of a tidal turbine in uniform steady flow. OCEAN ENGINEERING 2015; 110:51-61.

[9] Wang SG. Wake Velocity Characteristics of Horizontal-axis Tidal-current Turbine. TIANJIN UNIVERSITY MASTER THESIS 2017.

[10] Seo J, Lee SJ, Choi WS, Park ST, Rhee SH. Experimental study on kinetic energy conversion of horizontal-axis tidal stream turbine. RENEWABLE ENERGY 2016; 97:784-797. 
[11] Sufian SF, Li M, O'Connor BA. 3D modelling of impacts from waves on tidal turbine wake characteristics and energy output. RENEWABLE ENERGY 2017; 114:308-322.

[12] Baba-Ahmadi MH, Dong P. Numerical simulations of wake characteristics of a horizontal-axis tidal stream turbine using actuator line model. RENEWABLE ENERGY 2017; 113:669-678.

[13] Bromm M, Vollmer L, Kühn M. Numerical investigation of wind turbine wake development in directionally sheared inflow. WIND ENERGY 2017; 20:381-395.

[14] Lam WH, Chen L. Equations used to predict the velocity distribution within a wake from a horizontal-axis tidal-current turbine. OCEAN ENGINEERING 2014; 79:35-42.

[15] Albertson ML, Dai Y, Jensen RA,et al. Diffusion of submerged jets[J]. TRANSACTIONS OF THE AMERICAN SOCIETY OF CIVIL ENGINEERS 1950; 115(1):639-64.

[16] Blaauw H, Van de Kaa E. Erosion of bottom and sloping banks caused by the screw race of manoevring ships: DELFT HYDRAULICS 1978.

[17] Berger W, Felkel K, Hager M,et al. Courant provoque par les bateaux protection des berges et solution pour eviter l'erosion du lit du haut rhin. PIANC, $25^{\mathrm{TH}}$ CONGRESS 1981.

[18] Verhey H. The stability of bottom and banks subjected to the velocities in the propeller jet behind ships. INTERNATIONAL HARBOUR CONGRESS, 8th 1983.

[19] Hamill GA. Characteristics of the screw wash of a manoeuvring ship and the resulting bed scour. QUEEN'S UNIVERSITY OF BELFAST; 1987 [Ph.D. thesis].

[20] Hamill GA, Kee C, Ryan D. 3D Efflux Velocity Characteristics of Marine Propeller Jets. MARITIME ENGINEERING 2015; 168(2):62-75.

[21] Hamill GA, Kee C. Predicting axial velocity profiles within a diffusing marine propeller jet. OCEAN ENGINEERING 2016; 124:104-112.

[22] Lam WH. Simulations of a ship's propeller jet[D]. QUEEN'S UNIVERSITY OF BELFAST, 2008.

[23] Lam WH, Chen L, Hashim R. Analytical wake model of tidal current turbine. ENERGY 2015; 79:512-21.

[24] Versteegs HK, Malalasekera W. An Introduction to Computational Fluid Dynamics 
the Finite Volume Method. PRENTICE HALL, Essex 1995.

[25] Brinck D, Jeremejeff $N$. The development of a vertical axis tidal current turbine. MASTER OF SCIENCE THESIS EGI 2013:090.

[26] Zhao ZZ, Yan C, Wang TG, Xu BF, Zheng Y. Study on approach of performance improvement of VAWT employing double multiple stream tubes model. JOURNAL OF RENEWABLE AND SUSTAINABLE ENERGY 2017; 9(2): 10.1063/1.4979356

[27] Dyachuk E, Goude A. Simulating Dynamic Stall Effects for Vertical Axis Wind Turbines Applying a Double Multiple Streamtube Model. ENERGIES 2015; 8(2):13531372 .

[28] Dai YM, Lam WH. Numerical study of straight-bladed Darrieus-type tidal turbine. ENERGY 2009; 162:67-76.

[29] Guo FS, Jia M, Lam WH, Song YC, Zhao JF. Numerical simulation of verticalaxis tidal turbine array. ACTA ENERGIAE SOLARIS SINICA 2014; 35(9):1810-1815. 